\title{
Caso Díaz Loreto y otros vs. Venezuela
}

El 19 de noviembre de 2019, la Corte Interamericana de Derechos Humanos (en adelante "la Corte" o "este Tribunal") dictó una sentencia mediante la cual declaró que el Estado de Venezuela era responsable por la vulneración al derecho a la vida (artículo 4 de la Convención Americana) en perjuicio de Robert Ignacio Díaz Loreto, David Octavio Díaz Loreto y Octavio Ignacio Díaz Álvarez por los hechos que llevaron a su muerte en manos de funcionarios policiales del estado Aragua. El Estado también fue encontrado responsable por haber vulnerado el derecho a la integridad personal y a la libertad personal (artículos 5 y 7 de la Convención Americana) en perjuicio de Robert Ignacio Díaz Loreto por los hechos ocurridos luego de que este fuera montado herido en un vehículo de la policía. Asimismo se indicó que el Estado había violado las garantía al debido proceso (artículo 8.1 de la Convención) y a la integridad personal de los familiares de Robert Ignacio Díaz Loreto, David Octavio Díaz Loreto y Octavio Ignacio Díaz Álvarez por no haber cumplido con su deber de investigar, por el sufrimiento que les ocasionó sus muertes y por los actos de amenazas e intimidaciones de los cuales fueron víctimas a raíz de estos hechos.

\section{Hechos}

La Corte recordó que para la época de los hechos del caso existía en Venezuela y en particular en el estado Aragua un contexto de ejecuciones extrajudiciales por parte de funcionarios policiales. Ese contexto fue reconocido por instituciones públicas internas e internacionales.

Los hechos del caso ocurrieron el 6 de enero de 2003 en el sector de la Segundera de la ciudad de Cagua, Aragua, cuando el señor Robert Ignacio Díaz Loreto recibió disparos por parte de funcionarios del Cuerpo de Seguridad y 
Orden Público del estado Aragua (CSOPEA), y posteriormente fue trasladado al centro de salud Seguro Social de la Cornisa, en la ciudad de Cagua donde llegó sin vida.

En un segundo momento, David Octavio Díaz Loreto y Octavio Ignacio Díaz Álvarez recibieron disparos por parte de los funcionarios policiales. Posteriormente, fueron trasladados y dejados sin vida en el hospital José María Vargas, en la ciudad de Cagua.

A partir de esos hechos, las autoridades emprendieron diligencias de investigación y procesamiento de los presuntos responsables de las muertes de Robert Ignacio Díaz Loreto, David Octavio Díaz Loreto y Octavio Ignacio Díaz Álvarez, al cabo de los cuales fueron absueltos por sentencia en firme de 4 de septiembre de 2014. Por otra parte, la Corte comprobó que en el presente caso varios familiares de las tres víctimas fueron objeto de amenazas e intimidación durante el desarrollo de la investigación y del proceso.

\section{Excepciones preliminares}

La Corte declaró inadmisible las excepciones de falta de agotamiento de los recursos internos y otra de cuarta instancia interpuestas por el Estado por considerar que: a) recordó que el requisito de agotamiento de los recursos internos debe interpretarse en el sentido de que éste debe tener lugar para el momento en que se decida sobre la admisibilidad de la petición, y no para el momento de su presentación; b) la decisión sobre el alegado retardo injustificado requiere una evaluación de elementos íntimamente ligados al fondo de la controversia, y c) para que el alegato de cuarta instancia sea procedente, sería necesario que el solicitante busque que la Corte revise el fallo de un tribunal interno en virtud de su incorrecta apreciación de la prueba, los hechos o el derecho interno, sin que, a la vez, se alegue que tal fallo incurrió en una violación de tratados internacionales respecto de los que tenga competencia el Tribunal, lo cual no ha ocurrido en el presente caso. 


\section{Fondo}

\section{Derecho a la vida, libertad personal e integridad personal (artículos 4, 5, y 7 de la Convención Americana)}

La Corte constató que en el presente caso existen varias inconsistencias en la versión de los hechos presentada por el Estado en relación con la muerte de Robert Ignacio Díaz Loreto, David Octavio Díaz Loreto y Octavio Ignacio Díaz Álvarez que, si bien no le permiten determinar si se produjo efectivamente un enfrentamiento entre los funcionarios policiales y las presuntas víctimas, permiten concluir que el Estado no proporcionó ante esta Corte una explicación verosímil y satisfactoria sobre la forma en que fallecieron.

Sobre este punto, la Corte recordó en todo caso el uso de la fuerza por parte de agentes estatales que hayan producido la muerte o lesiones a una o más personas; corresponde al Estado la obligación de proveer una explicación satisfactoria y convincente de lo sucedido y desvirtuar las alegaciones sobre su responsabilidad, mediante elementos probatorios adecuados. La Corte constató que ello no ha ocurrido en el caso, dadas las contradicciones no esclarecidas y defectos de técnica criminalística que fueron señalados en la sentencia.

Por tal razón, el Tribunal encontró que el Estado era responsable por la vulneración al derecho a la vida contenido en el artículo 4 de la Convención Americana en perjuicio de Robert Ignacio Díaz Loreto, David Octavio Díaz Loreto y Octavio Ignacio Díaz Álvarez.

Por otra parte, la Corte constató que Robert Díaz Loreto apareció muerto en el Seguro Social de la Cornisa, por lo menos una hora después de que lo hirieran funcionarios de la policía del estado Aragua, cuando el centro de salud más cercano se encontraba a una distancia equivalente a quince minutos. Asimismo, la Corte halló evidencias que indicaban que Robert Díaz Loreto fue sometido a apremios físicos, probablemente durante el tiempo en que estuvo bajo custodia de la policía. Por ello concluyó que el Estado era responsable por una vulneración al derecho a la integridad personal, contenido en el artículo 5 de la Convención Americana, en perjuicio de Robert Díaz Loreto. 
Por último, la Corte resolvió que el Estado también era responsable por una violación al derecho a la libertad personal contenido en el artículo 7 de la Convención Americana en perjuicio de Robert Díaz Loreto por el tiempo durante el cual éste estuvo en custodia de los agentes policiales, el cual excede al menos en cuarenta y cinco minutos el requerido para desplazarse del lugar de los hechos al hospital donde finalmente fue llevado.

2. Derecho a las garantías judiciales y a la protección judicial (artículos 8.1 y 25 de la Convención Americana) y Convención Interamericana para Prevenir y Sancionar la Tortura

La Corte consideró que el Estado ha incurrido en una violación de la debida diligencia en la investigación de la muerte de Robert Ignacio Díaz Loreto, David Octavio Díaz Loreto y Octavio Ignacio Díaz Álvarez, puesto que: a) no se realizaron diligencias para verificar diversos aspectos de la versión de los familiares y otros testigos, como la reconstrucción de los hechos, las experticias a la ropa de las víctimas, la evidencia sobre el barro que tenía Robert Ignacio Díaz Loreto en su mucosa, pulmones y aparato digestivo, entre otros; y b) no se agotaron las líneas de investigación relacionadas con el contexto de ejecuciones extrajudiciales, pese a la existencia de indicios razonables.

Por otra parte, la Corte encontró sustento para concluir que existe una vulneración a la garantía judicial de plazo razonable contenida en el artículo 8.1 de la Convención en perjuicio de los familiares de Robert Ignacio Díaz Loreto, David Octavio Díaz Loreto y Octavio Ignacio Díaz Álvarez, por la excesiva duración de la investigación y del proceso vinculado con sus muertes.

A su vez, el Tribunal resolvió que estaba probada la falta de medidas de protección para los participantes en el proceso, lo cual se traduce en la vulneración por parte del Estado a las garantías contenidas en el artículo 8.1 de la Convención en perjuicio de los familiares de las tres víctimas.

Por último, la Corte estableció que, en el presente caso, el Estado es también responsable por una violación a los artículos 1, 6 y 8 de la Convención 
Interamericana para Prevenir y Sancionar la Tortura en perjuicio de los familiares de Robert Ignacio Díaz Loreto, toda vez que no se inició una investigación sobre hechos que podrían haber constituido malos tratos o torturas.

3. Derecho a la integridad personal de los familiares de Robert Ignacio Díaz Loreto, David Octavio Díaz Loreto y Octavio Ignacio Díaz Álvarez (artículo 5 de la Convención Americana)

El Tribunal consideró que -como consecuencia directa de la privación arbitraria a la vida de los señores Robert Ignacio Díaz Loreto, David Octavio Díaz Loreto y Octavio Ignacio Díaz Álvarez- sus familiares han padecido sufrimiento y angustia en detrimento de su integridad psíquica y moral. Del mismo modo, se refirió a los actos de hostigamiento y amenazas contra los familiares de Díaz Loreto, David Octavio Díaz Loreto y Octavio Ignacio Díaz Álvarez en el marco de las investigaciones judiciales sobre los hechos del presente caso. Por esos motivos, el Estado es responsable por la violación al artículo 5.1 de la Convención Americana, en relación con el artículo 1.1 del mismo instrumento, en perjuicio de los familiares de los señores Robert Ignacio Díaz Loreto, David Octavio Díaz Loreto y Octavio Ignacio Díaz Álvarez.

\section{Reparaciones}

La Corte estableció que su sentencia constituye, por sí misma, una forma de reparación y, adicionalmente, ordenó al Estado, en los plazos fijados en la sentencia: i) publicar la sentencia y su resumen oficial; ii) realizar un acto público de reconocimiento de responsabilidad internacional; iii) brindar el tratamiento, médico, psicológico o psiquiátrico, a las víctimas que lo soliciten; iv) llevar a cabo programas de capacitación sobre los estándares internacionales de derechos humanos en general y, en particular, a la policía del estado Aragua, y v) pagar la cantidad fijada en la sentencia por concepto de indemnización por daños 
materiales, inmateriales y costas y gastos, así como el reintegro al Fondo de Asistencia Legal de Víctimas de la Corte Interamericana, la cantidad erogada durante la tramitación del caso. 